\title{
PEMBELAJARAN GERAK SENAM BER-IRAMA DAPAT MENINGKATKAN KECERDASAN KINESTETIK TK ABA 3 SUMBERSARI
}

\author{
Bahtiar Hari Hardovi1 ${ }^{1}$, Misyana ${ }^{2)}$, Ahmad Bahriyanto ${ }^{3)}$, Dinda Putri Toyibah', \\ Universitas Muhammadiyah Jember \\ bahtiarharihardovi@unmuhjember.ac.id*, misyana@unmuhjember.ac.id, \\ ahmadbahriyanto@unmuhjember.ac.id, Dindatoyib@gmail.com
}

\begin{abstract}
Early childhood Education (PAUD) is one of the efforts to improve its physical, cognitive, social, spiritual and emotional changes. TK ABA III located in the village of sumbersari, Jember District is the educational place for children . Every Schooling definitely There are no a prob growing issues. The problems of the school ABA 3 Sumbersari Kindergarten school through interviews with the headmaster, Mrs. Erna Sri Rahayu, S.Pd. First, the manpower of lack of rhythmic gymnastics knowledge. Second lack of knowledgeable the watering gymnastics can improve kinesthetic. With a thus required implementation of empowerment rhythm training in Kindergarten School ABA 3 Sumbersari. Then need to be of Gymnastics training is rhythmic to the education personnel in School environment. In the Skeletal development and teknologi Learningtechnology. Then Teams Devotion Deliver Training rhythmic motion of Gymnastics . Includes a step foot motion technique that needs to be noticed by the participants, then participants follow and memorize and perform the movement repeatedly. Then the sculpte gives the technique of arm swing and the Pesesrta to perform repeatedly. And the last participant performs the movement in a rhythm. With a rhythmic gymnastics training the teachers become aware of the rhythmic gymnastics that is bungan by increasing the Kinestetian intelligence of early childhood.
\end{abstract}

Keywords: gymnastics rhythms; improve; kinesthetic Intelligence

$\begin{array}{cc}\text { Submit } & \text { Diterima } \\ 28 \text { Juni } 2020 & 30 \text { Juli } 2020\end{array}$

Dipublikasikan
31 Juli 2020

DOI : https://doi.org/10.33503/pambudi.v4i01.849

\section{ANALISIS SITUASI}

Masa anak usia dini adalah masa yang golden age atau biasa disebut masa ke amasan.(Wahyuningsih, 2014)sedangkan pendidikan anak usia dini merupakan tempat untuk mendidik yang ditujuakan pada anak sejak usia 5 tahun, akan lebih optimal apa bila usia 6 sampai 8 tahun.(Aulina, 2013) Pendidikan Jasmani bagi anak usia dini sangat perlu dilakukan agar dapat terjadi rangsangan tumbuh dan kembangnya anak. Tujuannya yaitu dapat mengembangkan potensi kemampuan fisik maupun intelktualnya secara optimal di lingkungan Pendidiakan Anak Usia Dini (PAUD).

Pendidikan Anak Usia Dini (PAUD) adalah salah satu upaya untuk meningkatkan perubahan fisik, kognitif, sosial, spiritual dan emosionalnya. Sehingga perlu diupayakan pendidikan yang tepat bagi anak sejak Usia Dini (Wahyuningsih, 2014).

Pada masa usia dini merupakan masa terjadinya kematangan fungsi-fungsi fisik dan psikis yang siap merespon stimulasi (rangsangan) yang diberikan oleh lingkungan. Masa ini merupakan masa untuk meletakkan dasar pertama dalam mengembangkan potensi fisik (motorik), intelektual, emosional, sosial, bahasa, seni dan moral spiritual.

Senam irama adalah gerakan senam ataupun bebas yang dibarengi dengan musik atau nyanyian sesuai dengan irama (Kunarti, Jubaedi, \& Nurseto, 2015). Kegiatan gerak senam ber-irama sangat melekat dan tidak dapat dipisahkan sehingga dalam pembelajaran jasmani terdapat gerak dan lagu ber-irama. Sehingga pada saat memberikan pembelajaran ada kegiatan bermain dan 
sambil belajar melalui gerak dan lagu berirama. Sehingga harapannya yaitu dapat berkembang kepekaan akan irama berkembangnya motoriknya. Kegiatan tersebut dapat melatih para pendidik untuk memberikan stimulus anak melui gerak berirama.

Dengan jabaran tersebut sangatlah penting pembelajaran geran senam ber-irama untuk anak usia dini untuk melatih mendengarkan irama serta konsentrasi untuk meningkatkan mendengarkan irama serta kecerdasan kinestetik.

Dari sebuah obsevasi terdapat fakta yang menunjukkan: (1) masih sedikitnya pendidik menerapkan pembelajaran gerak senam ber-irama di sekolah tersebut; (2) masih banyak peserta didik yang masih kurangnya perkembangan lokomotor dan psikomotoriknya.

Untuk menghadapi masalah-masalah tersebut, maka penangannannya harus dilakukan sedini mungkin, dimana anak perlu dibantu dalam meningkatkan kecerdasan musikal dan kecerdasan kinestetiknya yang diharapkan dengan cara pembelajaran gerak dan lagu yang dilakukan bersama-sama guru dan anak yang dapat membantu perkembangan otak, perkembangan indra, perkembangan kemampuan bahasa, dan kemampuan sosial anak usia dini (hingga 6 tahun). Pembelajaran gerak dan lagu ini akan membantu anak untuk melibatkan asfek motorik, intelektual dan emosi anak dalam sebuah kegiatan bersama.

\section{METODE PELAKSANAAN}

Langkah yang digunakan pertama menuju kesekolah TK ABA 3 Sumbersari kemudian memeberi pelatihan senam berirama di TK ABA 3 dengan pemberian materi dengan model ceramah, gerkan senam, tanya jawab, diskusi, dan materi praktek senam ber-irama dan bermain di lapangan untuk guru pendidik. Untuk memperlancar pelaksanaan maka disusunlah langkah-langkah sebagai berikut ini:
1. Memaparkan Materi pengetahuan tentang senam ber-irama dilaksanakan di kelas.

2. Memberi kesemapatan dengan memberikan sesi tanya jawab, diskusi bisa dilakukan di kelas dan di lapangan

3. Praktek gerak senam ber irama

4. Penguatan materi gerak senam ber-irama.

5. Penyerahan CD Kaset lagu seneam irama.

\section{HASIL DAN PEMBAHASAN}

Kegiatan pertama dengan melakukan kunjungan observasi pada tempat di TK ABA 3 Kaliwates. Dari hasil observasi terdapat identifikasi permasalahan guru terkait pembelajaran untuk meningkatkan kecerdasan kinestetik pada siswa TK ABA 3. Kemudian menawarkan memberikan solusi dengan memberikan pelatihan pembelajaran gerak senam berirama. Lalu membuat rangkaian gerakan senam berirama. Dari melakukan wawancara kemudian kami melakukan kesepakan dengan kepala sekolah TK ABA 3 Kaliwates untuk memberikan pelatihan senam ber-irama pada guru-guru disekolah tersebut.

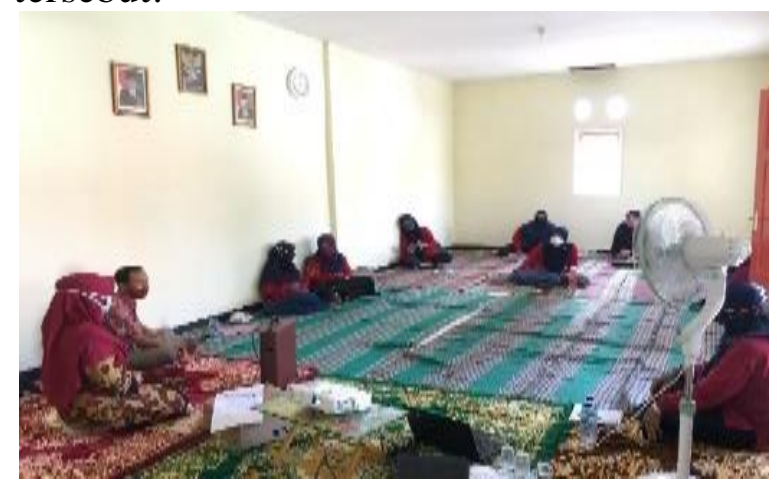

Gambar 1. Tahap wawan cara dengan para guru TK ABA 3 Sumbersari

Tujuan kami yaitu melakukan pengabdian masyarakat salah satu upaya untuk memberikan solusi dan meningkatkan kemampuan pendidik untuk memberikan pembelajaran senam berirama, sehingga dengan adanya pelatihan ini para guru di TK 
ABA dapat memberikan pengajaran senam ke serta didiknya.

Berikut bentuk kegiatan yang dilakukan di TK ABA 3 Sumbersari Jl. Riau no 49. Pertama memberikan pemahaman tentang materi senam ber-irama. Pada kegiatan ini kami mengenalkan senam irama kepada para guuru pendidik bahwasanya senam irama merupakan gerakan senam yang diklakukan dengan irama musik atau latihan bebas yang dilakukan secara berirama, senam irama atau ritmik biasanya dapat dilakukan menggunakan alat ataupun tanpa alat. Kemudian kami memberikan penjelasan bahwa sanya senam irama terdapat unsurunsur yang perlu di perhatikan bagi guru-guru pendidik anataranya senam irama diperlukan unsur kelenteukan, keseimbangan, keluwesan, fleksibiltas, kontinuitas dan ketepatan dengan irama. Selain itu para guru perlunya mengusai teknik gerakan senam irama agar tercapai gerakan-gerakan yang serasi dan bermanfaat bagi fisik dan kecerdasan mental. Hal ini agar sesuai dengan tujuan senam untuk membentuk kecerdasan kinestetik anak. Dan dijelaskan juga bahwasanya ada 3 hal yang harus ditekankan pad agerakan senam irama antaranya yaitu 1) ketepatan musik, 2) kelentukan, 3) kontinuitas gerakan senam. Kemudian memberi tahu bahwa sanya manfaat senam irama bagi kesehatan, bahwasanya sennam irama adalah olaharaga yang paling aman dan ramah lingkungan, kenapoa demikian pasalnya olahraga ini tidak membutukan kekuatan paru-paru atau jantung sehingga relatif sangat aman bagi anak, dan meminimalisir resiko mengalami pembengkokan tulang belang anak. Dari penjelasan pengenalan materi itu para guruguru menjadi kenal dan mengerti mengenai senam irama.

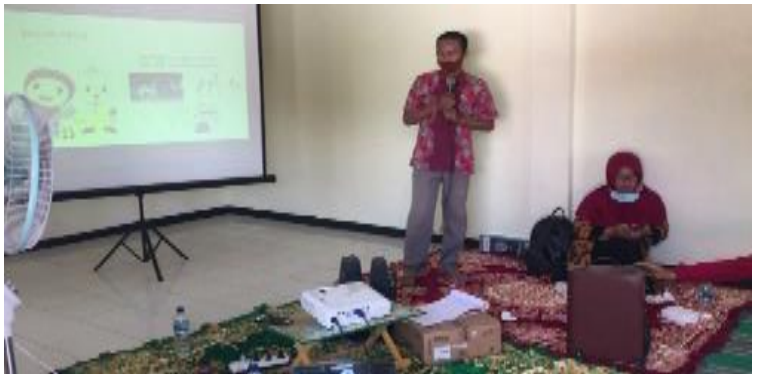

Gambar 2. Memberikan materi tentang senam berirama pada guru TK ABA 3 Sumbersari

Kemudian yang keduan memberikan materi tentang kecerdasan kinestetik anak, pada tahap ini pemateri mengenalkan karakter kecerdasan anak, di sampaikan pada guruguru bahwasanya kecerdasan anak ada sembilan yaitu 1) kecerdasan bahasa, 2) kecerdasan logika matematik, 3) kecerdasan visual, 4) kecerdasan kinestetik, 5) kecerdan musikal, 6) kecerdasan interpersonal, 7) kecerdasan intra personal, 8) kecerdasan naturalis, 9) kecerdasan moral. Lalu pemateri memberikan penjelasan tentang kecerdasan kinestetik bahwasanya kemampuan untuk menggabungkan antara fisik dan pikiran sehingga meng hasilkan gerakan yang sempurna.

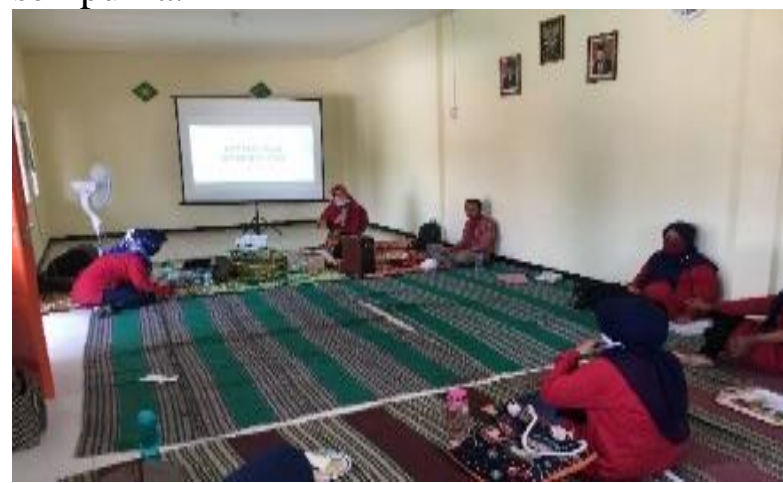

Gambar 3. Memberikan materi kecerdasan kinestetik pada guru TK ABA 3 Sumbersari

Kemudian memberikan pelatihan senam ber-irama pada guru TK ABA 3 Sumbersari. Meliputi Teknik Gerakan Langkah kaki yang perlu di perhatikan oleh peserta, kemudian peserta mengikuti dan menghafal dan melakukan Gerakan secara berulang-ulang. Kemudian pemateri meberikan Teknik ayunan lengan dan peserta melakukan 
secara berulang-ulang. Dan yang terakhir peserta melakukan Gerakan secara ber irama.

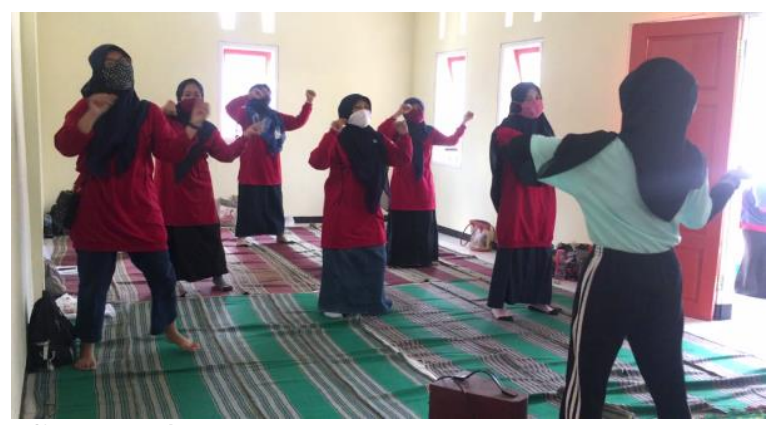

Gambar 4. Praktek senam irama kinestetik guru TK ABA 3 Sumbersari

Dari penjelasan diatas dapat diketahui kegiatan melakukan pengabdian di TK ABA 3 dapat dikatakan berhasil meberikan pelatihan senam ber-irama pada guru-guru TK ABA 3. Karna guru-guru suda dapat mengafalkan gerakan senam berima, sehingga nantinya dapat meberikan pembelajaran senam berirama pada siswa TK ABA 3 untuk meningkatkan kecerdasan kinestetik melalui senam berirama. Demikian serangakaian kegiatan pengabdian yang dilakukan oleh tim dosen UM Jember.

\section{KESIMPULAN}

Dari hasil yang dilakukan pelaksanaan kegiatan pelatihan, ada beberapa kesimpulan yaitu

1. Peserta dapat menerima informasi dan pengetahuan senam barirama bahwasannya senam berirama salah satu upaya untuk meningkatkan perubahan fisik dan juga psikomotorik dapat meningkatkan kecerdasannya

2. Dengan adanya pelatihan senam berirama para guru menjadi paham tentang senam ber-irama yang berhubungan dengan meningkatkan kecerdasan kinestetiknya anak usia dini.

3. Dari Lembaga diharapkan pengabdian ini menjadi sumbangan ilmu yang memberikan yang bermanfaat bagi semua Kepada pengabdi masyarakat diharapkan lebih lanjut tentang metode pembelajaran dalam bentuk buku pembelajaran senam berirama.

\section{DAFTAR PUSTAKA}

Aulina, C. N. (2013). Penanaman Disiplin Pada Anak Usia Dini. PEDAGOGIA: Jurnal Pendidikan. https://doi.org/10.21070/pedagogia.v2i1 .45

Kunarti, T. U., Jubaedi, A., \& Nurseto, F. (2015). Pengaruh Latihan Senam Irama Terhadap Peningkatan Kebugaran Jasmani. JUPE (Jurnal Penjaskesrek).

Wahyuningsih, S. (2014). Pendidikan Anak Usia Dini (PAUD). Media Prestasi Jurnal Pendidikan STKIP PGRI Ngawi.

Widhianawati, N. (2011). Pengaruh pembelajaran gerak dan lagu dalam meningkatkan kecerdasan musikal dan kecerdasan kinestetika anak usia dini. Academia.Edu.

Widayati, A. (2014). Penelitian Tindakan Kelas. Jurnal Pendidikan Akuntansi Indonesia. https://doi.org/10.21831/jpai.v6i1.1793

Widhianawati, N. (2011). Pengaruh pembelajaran gerak dan lagu dalam meningkatkan kecerdasan musikal dan kecerdasan kinestetika anak usia dini. Academia.Edu.

Nurjannah, N. (2017). Mengembangkan Kecerdasan Sosial Emosional Anak Usia Dini Melalui Keteladanan. Hisbah: Jurnal Bimbingan Konseling Dan Dakwah Islam. https://doi.org/10.14421/hisbah.2017.14 $1-05$

Nurjannah, N. (2017). Mengembangkan Kecerdasan Sosial Emosional Anak Usia Dini Melalui Keteladanan. Hisbah: Jurnal Bimbingan Konseling Dan Dakwah Islam. https://doi.org/10.14421/hisbah.2017.14 1-05

Widayati, A. (2014). Penelitian Tindakan Kelas. Jurnal Pendidikan Akuntansi Indonesia.

https://doi.org/10.21831/jpai.v6i1.1793 
Widhianawati, N. (2011). Pengaruh pembelajaran gerak dan lagu dalam meningkatkan kecerdasan musikal dan kecerdasan kinestetika anak usia dini. Academia.Edu. 